\title{
GEOTERMOBAROMETRIA EM ROCHAS DO COMPLEXO CAMPOS GERAIS AO NORTE DA ZONA DE CISALHAMENTO VARGINHA
}

\author{
ELIANE APARECIDA DEL LAMA*, MARCOS AURÉLIO FARIAS DE OLIVEIRA**, ANTENOR ZANARDO **
}

\begin{abstract}
GEOTHERMOBAROMETRY OF ROCKS OF THE CAMPOS GERAIS COMPLEX, NORTHERN PART OF VARGINHA SHEAR ZONE. Electron microprobe chemical analysis of mineral species from rocks of the southern part of Campos Gerais Complex, São Pedro da União-Nova Resende region (MG) show that the analysed species have a relatively homogeneous composition and that their paragenesis and geothermometric calculations indicate that the peak metamorphism took place at temperatures of $830-900^{\circ} \mathrm{C}$ and pressures of $12.5-15.0 \mathrm{kbar}$, the most common values being of $700-750^{\circ} \mathrm{C}$ and $11.8-12.1 \mathrm{kbar}$. The average geothermal gradient was of $21^{\circ} \mathrm{C} / \mathrm{km}$ is obtained and is similar to that of the Araxá-Canastra Group. The general estimated metamorphic conditions are of high pressure, at least higher than the Barrowian type.
\end{abstract}

Keywords: Campos Gerais Complex, Mineral chemistry, geothermobarometry, metamorphism.

\begin{abstract}
RESUMO A composição química de minerais de rochas do sul do Complexo Campos Gerais, região de São Pedro da União e Nova Resende (MG), obtida por microssonda eletrônica, possibilitando estudos geotermobarométricos. Os dados químicos mostram composição mineral relativamente homogênea nas diferentes unidades litológicas analisadas. As paragêneses minerais e a geotermometria indicaram que o auge do metamorfismo ocorreu a temperaturas de $830-900^{\circ} \mathrm{C}$ e pressões de $12.5-15.0 \mathrm{kbar}$, mais comumente de $700-750^{\circ} \mathrm{C}$ e 11.8-12.1 kbar, fornecendo um grau geotérmico médio da ordem de $21^{\circ} \mathrm{C} / \mathrm{Km}$, correlacionáveis com as do Grupo Araxá-Canastra. As condições metamórficas estimadas indicam ambiente de pressão superior ao do tipo barrowiano, pois não atingiu o campo de estabilidade da sillimanita, uma vez que a temperatura ultrapassou $800^{\circ} \mathrm{C}$.
\end{abstract}

Palavras-chave: Complexo Campos Gerais, química mineral, geotermobarometria, metamorfismo.

INTRODUÇÃO O Complexo Campos Gerais, objeto deste estudo, foi definido por Cavalcante et al. (1979) na região de Campos Gerais e engloba migmatitos e ortognaisses, ambos ocorrendo junto a faixas vulcano-sedimentares da Associação Barbacena. O Complexo limita-se a norte e noroeste com o Grupo Araxá-Canastra através de superfície de cavalgamento. A sul faz contato com gnaisses e granulitos do Complexo Varginha-Guaxupé através da Zona de Cisalhamento Varginha. A oeste é recoberto por rochas sedimentares carboníferas da Bacia do Paraná. A leste transiciona para gnaisses anatéxicos do Grupo Barbacena.

Litologicamente o Complexo Campos Gerais é composto dô duas porções distintas (Crosta et al. 1986, dentre outros). A porção norte consiste de terrenos gnáissico-graníticogreenstone belt e, na porção sul, por gnaisses graníticos e/ou aluminosos com granada e, às vezes, cianita e estaurolita, com intercalações de mica xistos, quartzitos, anfibólio gnaisses, anfibolitos e rochas metaultramáficas. Na porção sul do complexo, ocorrem rochas correlacionáveis aos Gnaisses Araxá-Canastra e Andrelândia, também denominado Complexo de Nappes de Guaxupé por Schrank et al (1990).

A faixa da porção meridional é considerada por Trouw et al (1984) como extensão dos Grupos Andrelândia e São João dei Rei. Soares et al. (1991) a denominaram de Complexo Varginha, enquanto Roig \& Schrank (1992) consideram-na pertencente ao Complexo de Nappes de Guaxupé, e Zanardo (1992) admite que a mesma pertence ao Grupo Araxá-Canastra com intercalações tectônicas diversas.

A partir de estudos termobarométricos verificou-se que a evolução metamórfica da porção sul do Complexo Campos Gerais é semelhante a do Grupo Araxá-Canastra e mostra condições báricas e litológias distintas do Complexo Varginha-Guaxupé (Del Lama 1993).
Serão apresentados aqui os dados de quimismo mineral, a aplicação de geotermobarometria e considerações sobre o metamorfismo das rochas do sul do Complexo Campos Gerais, nas regiões de São Pedro da União e Nova Resende (MG).

PETROGRAFIA As análises por microssonda eletrônica foram efetuadas em minerais de oito amostras de unidade de granada gnaisses, com freqüentes intercalações de muscovita quartzo xisto, granada anfibolitos/anfibolitos e rochas calcissilicáticas. Nas rochas mais aluminosas é freqüente a ocorrência de cianita milimétrica a centimétrica.

Os granada gnaisses caracterizam-se pela alternância de leitos milimétricos a centimétricos, ora mais claros com quartzo e feldspatos, ora escuros e com quartzo, feldspatos, biotita e anfibólio. São rochas leuco a mesocráticas, de coloração acinzentada e granulação variável. A foliação é dada principalmente pela orientação de quartzo, feldspato, granada e, localmente, biotita e anfibólio. Gradam para termos mais quartzosos, podendo aparecer cianita, hornblenda e quantidades consideráveis de biotita. Localmente intercalam-se com bandas de biotitito. Mineralogicamente são compostos por feldspato potássico (ortoclásio e/ou microclínio), quartzo, plagioclásio, biotita, granada, hastingsita (com ângulo $2 \mathrm{~V}$ variando de $60 \mathrm{a} 30^{\circ}$ ), hornblenda ou pargasita, epidoto, titanita, opacos, apatita, zircão, fluorita, carbonato, allanita, rutilo e restos de clinopiroxênio. A textura é granoblástica inequigranular bimodal a porfiroblástica lobulada a engrenada e orientada, com domínios poligonais, lepidoblásticos e, mais raramente, nematoblásticos.

As rochas calcissilicáticas têm coloração esverdeada, avermelhada quando alteradas, estrutura xistosa a gnáissica e granulação média a fina. A textura varia de granoblástica a nematoblática. Os minerais principais são diopsídio, gra-

* Bolsista da FAPESP, Pós-graduação em Geologia Regional

** Departamento de Petrologia e Metalogenia

Instituto de Geociências e Ciências Exatas - IGCE, Universidade Estadual Paulista - UNESP, Av. 24A n ${ }^{9} 1515$, Caixa Postal 178, CEP 13.506-900,

Rio Claro (SP) - Brasil, FAX (0195) 24-9644, FONE (0195) 34-0522 - ramal 209 
nada, quartzo, plagioclásio, escapolita, anfibólio e biotita/ flogopita. Os acessórios compreendem minerais opacos, apatita, rutilo, e turmalina. Clinozoisita, clorita e muscovita fina/sericita são minerais secundários.

Os granada anfibolitos/anfibolitos podem ser foliados ou não e, assim como as rochas calcissilicáticas, são constituídos por anfibólio, clinopiroxênio, plagioclásio, granada, epidoto, subordinadamente quartzo, titanita, clorita, apatita, opacos, rutilo e zircão. A textura varia de nematoblástica a granoblástica inequigranular poligonal a lobulada, localmente poiquiloblástica e decussada. Quando mais xistosos, apresentam dobras en chevron.

QUÍMICA MINERAL As análises de química mineral foram efetuadas em microssonda eletrônica CAMECA SX 50 , equipada por 4 espectrômetros, com um cristal TAP, um cristal PET e dois cristais LiF, no Departamento de Mineralogia e Petrologia, Instituto de Geociências da UnB. $\mathrm{O}$ cristal TAP detectou $\mathrm{Na}, \mathrm{Mg}, \mathrm{Al}$, Si e F; o cristal PET detectou $\mathrm{Ca}, \mathrm{Ti}, \mathrm{K}, \mathrm{Cl}$ e $\mathrm{Sr}$; e os cristais $\mathrm{LiF}$ detectaram $\mathrm{Fe}, \mathrm{Mn}, \mathrm{Ni}, \mathrm{Ba}$ e Zn. Durante a operação foi mantido um potencial de aceleração de $15 \mathrm{KV}$, corrente de $20 \mathrm{n}$ A, diâmetro do feixe de $1 \mu$ e tempo de exposição de $10 \mathrm{~s}$. Para a análise de plagioclásio utilizou-se diâmetro do feixe de 5 ou $10 \mu$. Os padrões utilizados foram naturais e sintéticos. $\mathrm{O} \mathrm{Fe}$ da granada e do piroxênio foi calculado usando-se a correção PAP.

Foram analisadas 8 amostras cuja localização encontra-se na Figura 1, e as análises químicas acham-se nas Tabelas 1 a 5 .

Para cada mineral foi calculada a média dos pontos analisados e, quando zonados, considerando-se separadamente o núcleo e a borda.

Analisaram-se cristais justapostos ou não, buscando verificar a importância da aplicação da geotermobarometria em ambos os contextos.
A composição química dos minerais analisados da porção sul do Complexo Campos Gerais é relativamente homogênea, com zoneamento mineral pouco freqüente, não apresentando grandes disparidades entre os minerais de diferentes unidades de rocha.

Nos gnaisses, as granadas classificam-se como almandina com até $25 \%$ de grossulária. Os cristais de plagioclásio são de oligoclásio. As biotitas apresentaram pequena variação composicional nos teores de $\mathrm{MgO}$ e $\mathrm{TiO}_{2}$.

Os anfibólios podem ou não apresentar bordas mais aluminosas, devido à substituição do Si pelo $\mathrm{Al}$ e é marcada por uma tonalidade verde azulada. São classificados como hornblenda Fe-pargasítica, segundo Leake (1978), ou Fehastingsita, segundo Deer et al. (1966) e Heinrich (1965). Ao microscópio, os anfibólios correspondem a uma Fehastingsita, pois possuem um pequeno ângulo $2 \mathrm{~V}$, apesar da proposta de Leake (1978) em favor da extinção desse nome. Porém esta característica é de fácil reconhecimento e distintiva para a Fe-hastingsita. Outro ponto favorável a essa denominação é a similaridade entre as análises químicas aqui obtidas e a encontrada por Deer et al. (1966) para a Fehastingsita. Ressalta-se, também, que a classificação de Leake (1978) baseia-se na quantificação de $\mathrm{Fe}^{++H}$. Uma vez que a microssonda eletrônica não fornece o $\mathrm{Fe}^{+++}$e $\operatorname{sim}$ o $\mathrm{Fe}^{\mathrm{T}}$, a estimativa do $\mathrm{Fe}^{* * *}$ pode subestimar seu valor, quando confrontado com as classificações existentes. E é justamente a quantidade de $\mathrm{Fe}^{+++}$que distingue a hastingsita e a pargasita na classificação de Leake (1978).

As granadas de anfibolitos são classificadas como almandina-piropo, com até 30\% de grossulária. Geralmente apresentam núcleos mais ricos em piropo e bordas mais ricas em almandina. Essa variação resulta da transformação de piroxênio em anfibólio, sendo o cálcio excedente incorporado pelo plagioclásio e/ou granada. Em rocha calcissilicática, a granada tem bordas mais ricas em grossulária, o que também está associado com a uralitização do piroxênio.

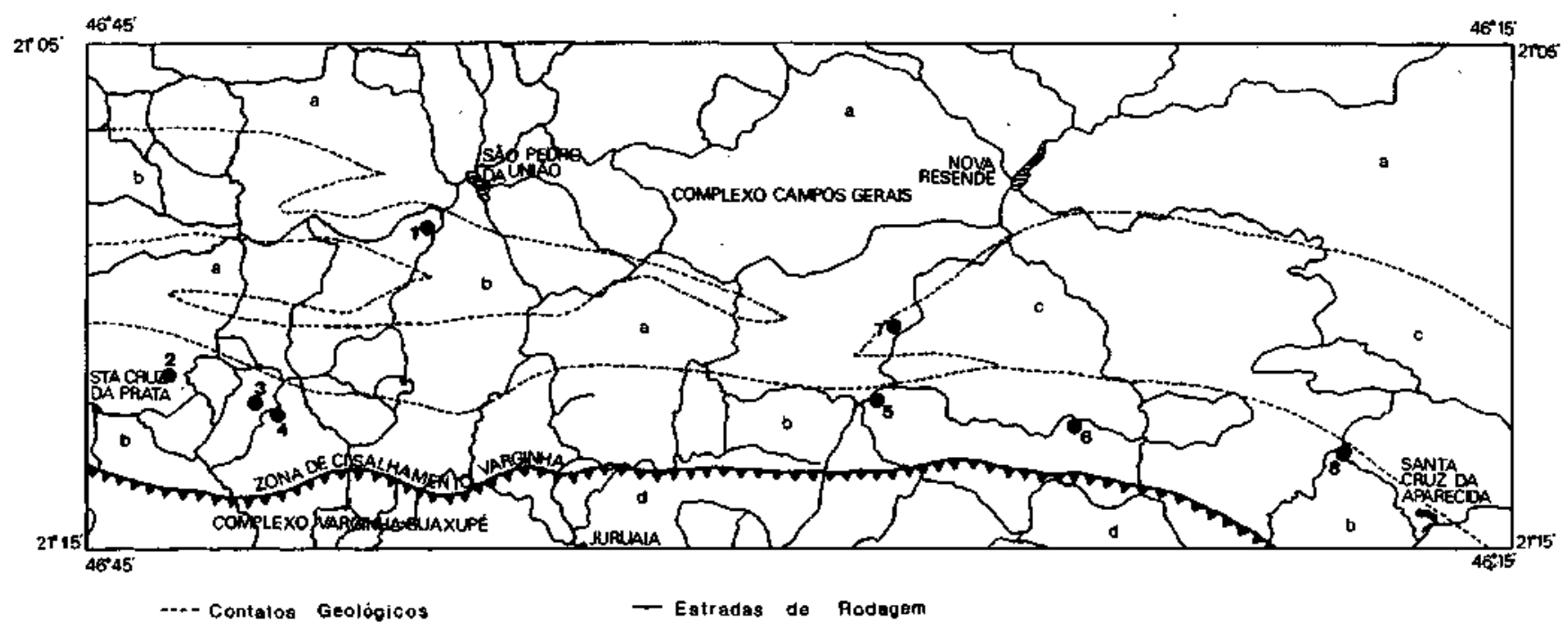

Figura 1 - Mapa geológico simplificado das regiões de São Pedro da União e Nova Resende, com a localização das amostras estudadas, $\boldsymbol{a}$ - Biotita e/ou hastingsita gnaisse granitico, com granada efluorita. $\boldsymbol{b}$ - Granada gnaisse com ou sem cianita, com intercalações de muscovita quartzo xisto, (granada) anfibolito e rocha calcissilicática. c - Metagrauvacas com porções anfibolíticas, quartzitos e xistos, e porções graníticas e migmatíticas. d- Gnaisse charnockítico: 1 - Granada-salitahornblenda gnaisse, 2 - Anfibólio-biotita-granada gnaisse, 3 - Granada-clinopiroxênio anfibolito, 4 - Biotita-gr-anadaanfibólio gnaisse monzogranítico, 5 - Granada-anfibolito, 6 - Granada-diopsídio gnaisse, 7 - Granada-epidoto-biotita xisto, $\boldsymbol{8}$ - Biotita-granada gnaisse granítico

Figure 1 - Simplified geologic map of the São Pedro da União and Nova Resende regions, with location of studied samples, a Biotite and/or hastingsite granitic gneiss, with garnet and fluorite. b. Garnet gneiss with or without kyanite, with intercalations of muscovite quartz schist, (garnet) amphibolite and calcsilicate. c. Metagreywackes with amphibolite, quartzite and schist intercalations, locally with granite and migmatite. d. Charnockitic gneiss: 1. Garnet-salite-hornblende gneiss, 2. Amphibole-biotite-garnet gneiss,3. Garnet-clinopyroxene amphibolite, 4. Biotite-garnet-amphibole monzogranitic gneiss, 5. Garnet amphibolite, 6. Garnet-diopside gneiss, 7. Garnet-epidote-biotite schist, 8 - Biotite-garnet granitic gneiss 
Tabela 1 - Dados de análise de granadas $(N=$ núcleo, $B$ - borda) por microssonda eletrônica

Table 1- Electron microprobe analysis of garnet $(\mathrm{N}=$ center, $\mathrm{B}=$ rim $)$

\begin{tabular}{|c|c|c|c|c|c|c|c|c|c|c|c|}
\hline GRT & $1 \mathrm{~N}$ & 1B & 3 & $3 \mathrm{~N}$ & 3B & 4 & 5 & $6 \mathrm{~N}$ & $6 \mathrm{~B}$ & 7 & 8 \\
\hline $\begin{array}{l}\mathrm{SiO}_{2} \\
\mathrm{TiO}_{2} \\
\mathrm{Al}_{2} \mathrm{O}_{3} \\
\mathrm{Cr}_{2} \mathrm{O}_{3} \\
\mathrm{Fe}_{2} \mathrm{O}_{3} \\
\mathrm{FeO} \\
\mathrm{MnO} \\
\mathrm{MgO} \\
\mathrm{CaO} \\
\text { TOTAL }\end{array}$ & $\begin{array}{r}38,15 \\
0,03 \\
21,63 \\
0,06 \\
0,43 \\
21,81 \\
0,63 \\
6,74 \\
9,94 \\
99,42\end{array}$ & $\begin{array}{r}37,88 \\
0,02 \\
21,61 \\
0,07 \\
0,27 \\
22,54 \\
1,02 \\
5,30 \\
10,95 \\
99,46\end{array}$ & $\begin{array}{r}36,75 \\
0,04 \\
20,55 \\
0,03 \\
0,49 \\
30,09 \\
0,93 \\
0,94 \\
9,10 \\
98,91\end{array}$ & $\begin{array}{r}38,87 \\
0,04 \\
22,13 \\
= \\
0,03 \\
22,57 \\
0,57 \\
6,88 \\
9,24 \\
100,33\end{array}$ & $\begin{array}{r}38,14 \\
0,05 \\
21,66 \\
0,07 \\
0,10 \\
23,76 \\
0,86 \\
5,84 \\
8,93 \\
99,41\end{array}$ & $\begin{array}{r}36,35 \\
0,06 \\
20,33 \\
-, 9 \\
0,92 \\
30,70 \\
0,74 \\
1,03 \\
9,20 \\
99,33\end{array}$ & $\begin{array}{r}38,70 \\
0,04 \\
21,94 \\
0,13 \\
0,53 \\
18,38 \\
0,46 \\
9,19 \\
10,15 \\
99,52\end{array}$ & $\begin{array}{r}38,42 \\
0,09 \\
21,95 \\
0,09 \\
0,30 \\
22,56 \\
0,49 \\
9,07 \\
6,93 \\
99,90\end{array}$ & $\begin{array}{r}38,46 \\
0,08 \\
21,90 \\
0,10 \\
0,26 \\
23,35 \\
0,50 \\
8,55 \\
6,70 \\
99,90\end{array}$ & $\begin{array}{r}36,85 \\
0,04 \\
20,20 \\
- \\
1,49 \\
23,90 \\
2,79 \\
0,81 \\
13,44 \\
99,52\end{array}$ & $\begin{array}{c}36,85 \\
21,04 \\
0,03 \\
- \\
30,62 \\
0,65 \\
1,25 \\
8,68 \\
99,13\end{array}$ \\
\hline $\begin{array}{l}\mathrm{Si}^{+4} \\
\mathrm{Ti}^{+4} \\
\mathrm{Al}^{+3} \\
\mathrm{Cr}^{+3} \\
\mathrm{Fe}^{+3} \\
\mathrm{Fe}^{+2} \\
\mathrm{Mn}^{+2} \\
\mathrm{Mg}^{+2} \\
\mathrm{Ca}^{+2} \\
\mathrm{TO}^{+2} \mathrm{TAL} \\
\mathrm{O}^{-2}\end{array}$ & $\begin{array}{c}5,92 \\
- \\
3,96 \\
0,01 \\
0,05 \\
2,83 \\
0,08 \\
1,55 \\
1,65 \\
16,05 \\
24,00\end{array}$ & $\begin{array}{c}5,91 \\
--97 \\
3,97 \\
0,01 \\
0,03 \\
2,94 \\
0,13 \\
1,23 \\
1,83 \\
16,05 \\
24,00\end{array}$ & $\begin{array}{r}5,98 \\
0,01 \\
3,94 \\
- \\
0,06 \\
4,09 \\
0,13 \\
0,23 \\
1,59 \\
16,02 \\
24,00\end{array}$ & $\begin{array}{c}5,96 \\
- \\
4,00 \\
- \\
2,89 \\
0,07 \\
1,57 \\
1,52 \\
16,03 \\
24,00\end{array}$ & $\begin{array}{c}5,96 \\
0,01 \\
3,99 \\
0,01 \\
0,01 \\
3,10 \\
0,12 \\
1,36 \\
1,49 \\
16,07 \\
24,00\end{array}$ & $\begin{array}{c}5,92 \\
0,01 \\
3,90 \\
0,11 \\
4,18 \\
0,10 \\
0,25 \\
1,60 \\
16,07 \\
24,00\end{array}$ & $\begin{array}{c}5,91 \\
- \\
3,94 \\
0,02 \\
0,06 \\
2,34 \\
0,06 \\
2,09 \\
1,66 \\
16,08 \\
24,00\end{array}$ & $\begin{array}{l}5,89 \\
0,02 \\
3,97 \\
0,01 \\
0,03 \\
2,89 \\
0,06 \\
2,07 \\
1,14 \\
16,08 \\
24,00\end{array}$ & $\begin{array}{r}5,92 \\
0,02 \\
3,97 \\
0,01 \\
0,03 \\
3,00 \\
0,07 \\
1,96 \\
1,11 \\
16,09 \\
24,00\end{array}$ & $\begin{array}{r}5,93 \\
-- \\
3,83 \\
- \\
0,18 \\
3,22 \\
0,38 \\
0,19 \\
2,32 \\
16,05 \\
24,00\end{array}$ & $\begin{array}{c}5,96 \\
- \\
4,01 \\
- \\
- \\
4,15 \\
0,09 \\
0,30 \\
1,51 \\
16,03 \\
24,00\end{array}$ \\
\hline $\begin{array}{l}\text { UVR } \\
\text { ADR } \\
\text { GRS } \\
\text { PRP } \\
\text { SPS } \\
\text { ALM }\end{array}$ & $\begin{array}{r}0,2 \\
1,3 \\
25,5 \\
25,4 \\
1,4 \\
46,2\end{array}$ & $\begin{array}{r}0,2 \\
0,8 \\
28,7 \\
20,1 \\
2,2 \\
47,9\end{array}$ & $\begin{array}{r}0,1 \\
1,6 \\
24,6 \\
3,8 \\
2,1 \\
67,9\end{array}$ & $\begin{array}{r}0,2 \\
24,8 \\
26,0 \\
1,2 \\
47,8\end{array}$ & $\begin{array}{r}0,2 \\
0,4 \\
24,0 \\
22,4 \\
1,9 \\
51,3\end{array}$ & $\begin{array}{r}- \\
2,8 \\
23,2 \\
4,1 \\
1,7 \\
68,2\end{array}$ & $\begin{array}{r}0,4 \\
1,5 \\
25,0 \\
34,0 \\
1,0 \\
38,1\end{array}$ & $\begin{array}{r}0,3 \\
1,0 \\
17,1 \\
33,7 \\
1,0 \\
47,0\end{array}$ & $\begin{array}{r}0,3 \\
0,9 \\
16,7 \\
32,0 \\
1,1 \\
49,0\end{array}$ & $\begin{array}{r}- \\
4,5 \\
33,4 \\
3,2 \\
6,2 \\
52,7\end{array}$ & $\begin{array}{r}0,1 \\
- \\
24,8 \\
5,0 \\
1,5 \\
67,9\end{array}$ \\
\hline
\end{tabular}

As análises de clinopiroxênio de anfibolitos (Tab. 5) diferenciam-se principalmente pelo teor de $\mathrm{A}_{2} \mathrm{O}_{3}$, sendo que duas apresentam teores bastante elevados, podendo atingir até $8 \%$. $\mathrm{O} \mathrm{Na} \mathrm{Na}_{2} \mathrm{O}$ também ocorre em teores mais elevados que os usuais, em torno de 1,2-1,6\%. Esses valores mostram que esses piroxênios podem ter características de piroxênios sódicos do tipo onfacita, indicando que as amostras 5 e 6 pbdem ser eclogitos.

No clinopiroxênio típico de eclogitos, a onfacita, o $\mathrm{Al}$ ocupa principalmente as posições de coordenação 6 , enquanto no de granulitos a maior parte do Al situa-se nas posições de coordenação 4 . Nas duas amostras estudadas, o Al ocupa, no mínimo, $50 \%$ da posição de coordenação 6.

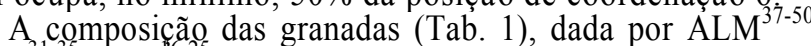
PRP $^{31-35}$ GRS $^{\text {Pr-25 }}$, é compatível também com a fácies eclogito e, no gráfico triangular de Smulikowski (1968), situam-se no campo de granadas que ocorrem em eclogitos comuns.

Comparando com os eclogitos descritos em São Sebastião do Paraíso de Hoppe et al. (1985), os teores de Al e Na do clinopiroxênio das amostras estudadas são maiores, assim como a porcentagem da molécula de piropo.

O plagioclásio é do tipo andesina e apresenta zoneamento inverso, marcado pelo enriquecimento de $\mathrm{CaO}$ nas bordas (Tab. 3), relacionado com a uralitização do piroxênio e consumo de granada.

Os anfibólios geralmente apresentam zoneamento (Tab. 4), indicado principalmente pela variação de cor, com núcleos mais castanhos, que podem ser mais ricos em $\mathrm{Al}$ ou $\mathrm{Mg}$ e Ti, e bordas esverdeadas, e são classificados como Fepargasita a hornblenda Fe-pargasítica (segundo Leake 1978).

Sendo assim, as variações composicionais apresentadas são oriundas de retrometamorfismo.
GEOTERMOBAROMETRIA Para a quantificação da temperatura foram utilizados os termômetros clinopiroxênio-granada (cpx-grt) e granada-hornblenda (grt-hbl) de Powell (1985), hornblenda-plagioclásio (hbl-pl) de Blundy \& Holland (1990), e biotita-granada (bt-grt) de Holdaway \& Lee (1977) e Ferry \& Spear (1978). O pequeno número de geobarômetros utilizados, nem sempre em condições ideais, exigiu maior acuidade na quantificação da pressão. Foram utilizados os barômetros de Newton \& Perkins (1982) para granada-clinopiroxênio/ortopiroxênio-plagioclásio-quartzo (grt-cpx/opx-pl-qtz) e Kohn \& Spear (1990) para granadahornblenda-plagioclásio-quartzo (grt-hbl-pl-qtz).

A concordância entre vários termômetros e barômetros sugere que a assembléia mineralógica está em equilíbrio ou foi reajustada para as mesmas condições metamórficas, pois é improvável que termômetros e barômetros independentes registrem as mesmas temperaturas e pressões se as paragêneses estiverem desequilibradas.

A similaridade dos geotermômetros indica tanto auge metamórfico quanto reajustes retrometamórficos, e com amarrações petrológicas foi possível identificar o significado das condições de P e T apontadas pelos geotermobarômetros. Como exemplo, existe uma relação sistemática entre as composições de plagioclásio e anfibólio Ca coexistentes e o grau metamórfico. Em geral, plagioclásio torna-se mais cálcico e anfibólio mais sódico e aluminoso com aumento do grau metamórfico (Spear 1981). No caso das amostras estudadas, tanto petrográfíca como quimicamente, ocorre o inverso da relação citada, ou seja, o plagioclásio apresenta bordas mais cálcicas e o anfibólio bordas mais aluminosas com a queda da temperatura (Tabs. 3 e 4). Esse zoneamento não indica metamorfísmo progressivo, mas retrometamorfismo. Com a destruição do piroxênio, parte 
Tabela 2 - Dados de análise de biotitas por microssonda eletrônica

Table 2 - Electron microprobe analysis of biotite

\begin{tabular}{|c|c|c|c|c|}
\hline BT & 2 & 4 & 7 & 8 \\
\hline $\begin{array}{l}\mathrm{SiO}_{2} \\
\mathrm{TiO}_{2} \\
\mathrm{Al}_{2} \mathrm{O}_{3} \\
\mathrm{C}_{2} \mathrm{O}_{3} \\
\mathrm{MgO} \\
\mathrm{CaO} \\
\mathrm{MnO} \\
\mathrm{FeO} \\
\mathrm{NiO} \\
\mathrm{BaO} \\
\mathrm{Na}_{2} \mathrm{O} \\
\mathrm{K}_{2} \mathrm{O} \\
\mathrm{H}_{2} \mathrm{O} \\
\mathrm{F}_{2} \mathrm{O} \\
\mathrm{Cl}_{2} \mathrm{O} \\
\text { TOTAL }\end{array}$ & $\begin{array}{c}34,00 \\
4,09 \\
14,93 \\
0,03 \\
3,26 \\
0,07 \\
28,82 \\
0,01 \\
0,17 \\
0,06 \\
9,25 \\
3,58 \\
0,18 \\
0,09 \\
98,54\end{array}$ & $\begin{array}{c}33,88 \\
3,71 \\
15,01 \\
0,01 \\
3,47 \\
0,04 \\
29,08 \\
0 \\
0,30 \\
0,06 \\
9,00 \\
3,54 \\
0,23 \\
0,11 \\
98,44\end{array}$ & $\begin{array}{c}34,49 \\
3,18 \\
15,73 \\
0,04 \\
5,75 \\
0,32 \\
0,32 \\
25,62 \\
0,02 \\
0,39 \\
0,06 \\
9,50 \\
3,67 \\
0,15 \\
0,06 \\
98,98\end{array}$ & $\begin{array}{c}34,65 \\
4,14 \\
15,89 \\
0,02 \\
4,63 \\
0,01 \\
0,05 \\
25,90 \\
0,03 \\
0,29 \\
0,08 \\
9,09 \\
3,44 \\
0,50 \\
0,26 \\
98,98\end{array}$ \\
\hline $\begin{array}{l}\mathrm{O}=\mathrm{F} \\
\mathrm{O}=\mathrm{Cl} \\
\text { TOTAL }\end{array}$ & $\begin{array}{l}-0,07 \\
-0,02 \\
98,45\end{array}$ & $\begin{array}{l}-0,10 \\
-0,02 \\
98,32\end{array}$ & $\begin{array}{l}-0,06 \\
-0,02 \\
98,90\end{array}$ & $\begin{array}{l}-0,21 \\
-0,06 \\
98,71\end{array}$ \\
\hline $\begin{array}{l}\mathrm{Si}^{+4} \\
\mathrm{Ti}^{+4} \\
\mathrm{Al}^{+3} \\
\mathrm{Cr}^{+3} \\
\mathrm{Mg}^{+2} \\
\mathrm{Ca}^{+2} \\
\mathrm{Mn}^{+2} \\
\mathrm{Fe}^{+3} \\
\mathrm{Ni}^{+2} \\
\mathrm{Ba}^{+2} \\
\mathrm{Na}^{+1} \\
\mathrm{~K}^{+1} \\
\text { TOTAL }\end{array}$ & $\begin{array}{c}5,53 \\
0,50 \\
2,86 \\
0,79 \\
0,01 \\
0,91 \\
3,92 \\
- \\
0,01 \\
0,02 \\
1,92 \\
15,56\end{array}$ & $\begin{array}{c}5,53 \\
0,45 \\
2,88 \\
0,84 \\
- \\
- \\
3,97 \\
- \\
0,02 \\
0,02 \\
1,87 \\
15,58\end{array}$ & $\begin{array}{c}5,50 \\
0,38 \\
2,95 \\
1,37 \\
- \\
0,04 \\
3,42 \\
-\overline{0} \\
0,02 \\
0,01 \\
1,93 \\
15,62\end{array}$ & $\begin{array}{c}5,55 \\
0,50 \\
3,00 \\
- \\
1,10 \\
- \\
0,01 \\
3,47 \\
- \\
0,02 \\
0,02 \\
1,86 \\
15,53\end{array}$ \\
\hline
\end{tabular}

do Ca liberado entra na estrutura do plagioclásio, enriquecendo suas bordas. O crescimento do anfibólio, usando a passagem de fluido intersticial rico em $\mathrm{Na}$, resulta em bordas mais aluminosas, devido à substituição do Si pelo Al. Assim, a temperatura superior calculada nessas situações não é considerada, uma vez que elas são provocadas pelas mudanças composicionais oriundas de retrometamorfismo.

Muitas vezes, a utilização do termômetro hbl-pl indica temperaturas inferiores às de outros termômetros, coerentes com a biotitização do anfibólio e a albitização do plagioclásio.

O intervalo de pressão utilizado nos termômetros foi balizado (Fig. 2) na reação almandina $-f$ rutilo = ilmenita

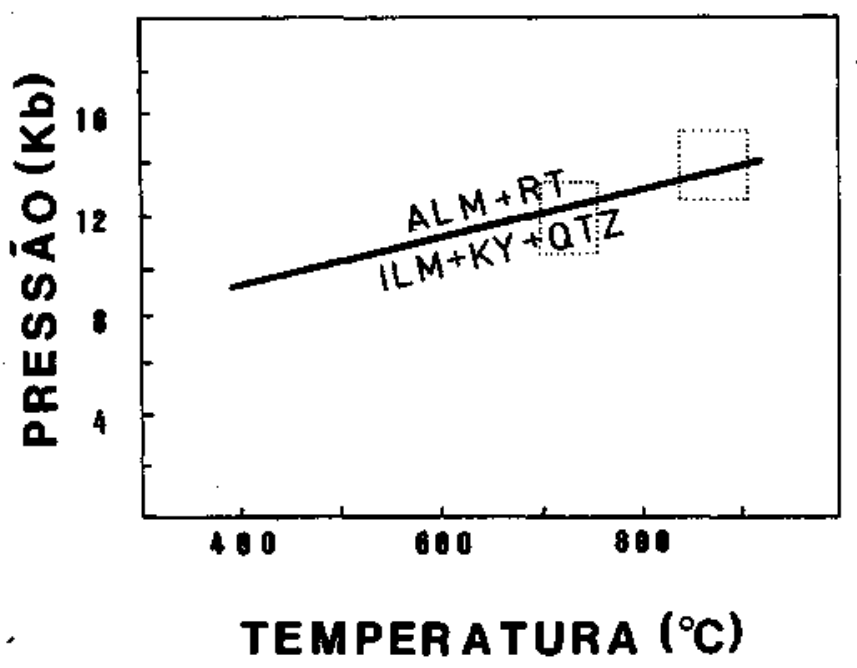

Figura 2 - Reação almandina + rutilo = ilmenita + cianita + quartzo (Bohlen et al. 1983), com a localização do inter. valo $P$-T estimado

Figure $2-$ Reaction almandine + rutile $=$ ilmenite + kyanite + quartz, with location of estimated P-T range

Tabela 3 - Dados de análise defeldspatos $(\boldsymbol{N}=$ núcleo, $\boldsymbol{B}=$ borda $)$ por microssonda eletrônica Tfeble 3 - Electron microprobe analysis of feldspars $(\mathbf{N}=$ center, $\mathbf{B}=$ rim $)$

\begin{tabular}{|c|c|c|c|c|c|c|c|c|c|c|}
\hline PL & IN & $1 B$ & 2 & $3 \mathbf{N}$ & 3B & 4 & $5 \mathrm{~N}$ & $5 B$ & $6 \mathrm{~N}$ & $6 \mathrm{~B}$ \\
\hline $\begin{array}{l}\mathrm{SiO}_{2} \\
\mathrm{Al}_{2} \mathrm{O}_{3} \\
\mathrm{Fe}_{2} \mathrm{O}_{3} \\
\mathrm{CaO} \\
\mathrm{SrO} \\
\mathrm{BaO} \\
\mathrm{Na}_{2} \mathrm{O} \\
\mathrm{K}_{2} \mathrm{O}\end{array}$ & $\begin{array}{r}60,28 \\
24,98 \\
0,08 \\
6,95 \\
0,06 \\
0,09 \\
7,70 \\
0,22\end{array}$ & $\begin{array}{r}58,93 \\
25,56 \\
0,16 \\
7,80 \\
0,06 \\
- \\
7,14 \\
0,24\end{array}$ & $\begin{array}{r}64,87 \\
22,39 \\
0,08 \\
3,60 \\
0,04 \\
0,09 \\
9,09 \\
0,15\end{array}$ & $\begin{array}{r}60,63 \\
25,09 \\
0,20 \\
7,11 \\
0,03 \\
0,12 \\
7,56 \\
0,13\end{array}$ & $\begin{array}{r}59,42 \\
25,84 \\
0,16 \\
7,83 \\
0,03 \\
0,04 \\
7,31 \\
0,10\end{array}$ & $\begin{array}{r}64,86 \\
21,85 \\
0,15 \\
3,18 \\
0,06 \\
0,06 \\
9,81 \\
0,15\end{array}$ & $\begin{array}{r}60,99 \\
24,62 \\
0,06 \\
6,67 \\
0,02 \\
0,03 \\
7,91 \\
0,08\end{array}$ & $\begin{array}{r}60,83 \\
25,01 \\
0,10 \\
6,96 \\
0,02 \\
0,05 \\
7,61 \\
0,08\end{array}$ & $\begin{array}{r}62,12 \\
23,92 \\
0,12 \\
5,77 \\
0,12 \\
0,01 \\
7,84 \\
0,68\end{array}$ & $\begin{array}{r}61,47 \\
24,45 \\
0,13 \\
6,29 \\
0,08 \\
0,10 \\
7,84 \\
0,45\end{array}$ \\
\hline TOTAL & 100,37 & 99,89 & 100,32 & 100,87 & 100,73 & 100,12 & 100,38 & 100,66 & 100,57 & 100,81 \\
\hline $\begin{array}{l}\mathrm{Si}^{++1} \\
\mathrm{Al}^{+3} \\
\mathrm{Fe}^{+3}\end{array}$ & $\begin{array}{l}2,68 \\
1,31 \\
-\end{array}$ & $\begin{array}{l}2,64 \\
1,35 \\
-\end{array}$ & $\begin{array}{l}2,84 \\
1,15 \\
-\quad\end{array}$ & $\begin{array}{l}2,68 \\
1,30\end{array}$ & $\begin{array}{l}2,64 \\
1,35\end{array}$ & $\begin{array}{l}2,86 \\
1,3\end{array}$ & $\begin{array}{l}2,70 \\
1,29\end{array}$ & $\begin{array}{l}2,69 \\
1,30\end{array}$ & $\begin{array}{l}2,75 \\
1,25\end{array}$ & $\begin{array}{l}2,72 \\
1,27\end{array}$ \\
\hline $\begin{array}{l}\mathrm{Ca}^{+2} \\
\mathrm{Sr}^{+2}\end{array}$ & 0,33 & 0,37 & 0,16 & 0,33 & 0,37 & 0,15 & 0,31 & 0,33 & 0,27 & 0,30 \\
\hline $\mathrm{Ba}^{+2}$ & - & - & - & - & $=$ & - & - & - & - & - \\
\hline $\begin{array}{l}\mathrm{Na}^{+1} \mathbf{1} \\
\mathrm{K}^{+1}\end{array}$ & $\begin{array}{l}0,66 \\
0,01\end{array}$ & $\begin{array}{l}0,62 \\
0,01\end{array}$ & $\begin{array}{l}0,77 \\
0,01\end{array}$ & $\begin{array}{l}0,64 \\
0,01\end{array}$ & $\begin{array}{l}0,63 \\
-\end{array}$ & $\begin{array}{l}0,84 \\
0,11\end{array}$ & $\begin{array}{l}0,68 \\
-\end{array}$ & 0,65 & $\begin{array}{l}0,67 \\
0,04\end{array}$ & $\begin{array}{l}0,67 \\
0,02\end{array}$ \\
\hline $\begin{array}{l}\mathrm{AB} \\
\mathrm{OR} \\
\mathrm{AN}\end{array}$ & $\begin{array}{r}65,9 \\
1,2 \\
32,9\end{array}$ & $\begin{array}{r}61,5 \\
1,4 \\
37,1\end{array}$ & $\begin{array}{r}81,3 \\
0,9 \\
17,8\end{array}$ & $\begin{array}{r}66,4 \\
0,7 \\
33,9\end{array}$ & $\begin{array}{r}62,4 \\
0,6 \\
37,0\end{array}$ & $\begin{array}{r}84,0 \\
0,8 \\
15,1\end{array}$ & $\begin{array}{r}67,9 \\
0,4 \\
31,7\end{array}$ & $\begin{array}{r}66,1 \\
0,4 \\
33,4\end{array}$ & $\begin{array}{r}68,3 \\
3,9 \\
27,8\end{array}$ & $\begin{array}{r}67,5 \\
2,6 \\
29,9\end{array}$ \\
\hline
\end{tabular}


Tabela 4 - Dados de análise de anfibólios $\left(N=\right.$ núcleo, $B=$ borda) por microssonda eletrônica. $O \mathrm{Fe}^{+++}$foi calculado como sugerido por Stout (1972)

Table 4 - Electron microprobe analysis of amphibole $\left(\mathrm{N}=\right.$ center, $\mathrm{B}=$ rim). $\mathrm{Fe}^{+++}$calculated according to Stout $(1972)$

\begin{tabular}{|c|c|c|c|c|c|c|c|c|}
\hline ANF & $1 \mathrm{~N}$ & 1B & $2 \mathrm{~N}$ & $2 B$ & 3 & 4 & 5 & 6 \\
\hline $\begin{array}{l}\mathrm{SiO}_{2} \\
\mathrm{TiO}_{2} \\
\mathrm{Al}_{2} \mathrm{O}_{3} \\
\mathrm{Cr}_{2} \mathrm{O}_{3} \\
\mathrm{FOO} \\
\mathrm{MnO} \\
\mathrm{MgO} \\
\mathrm{CaO} \\
\mathrm{NiO} \\
\mathrm{ZnO} \\
\mathrm{Na}_{2} \mathrm{O} \\
\mathrm{K}_{2} \mathrm{O} \\
\mathrm{H}_{2} \mathrm{O} \\
\mathrm{Cl} \\
\mathrm{F} \\
\mathrm{TOTAL} \\
\mathrm{O}=\mathrm{F} \\
\mathrm{O}=\mathrm{Cl}\end{array}$ & $\begin{array}{r}42,20 \\
1,19 \\
14,06 \\
0,08 \\
13,87 \\
0,21 \\
10,30 \\
12,53 \\
0,07 \\
0,03 \\
1,45 \\
1,03 \\
1,95 \\
0,01 \\
0,09 \\
99,07 \\
-0,03 \\
0,00\end{array}$ & $\begin{array}{r}40,92 \\
0,94 \\
15,90 \\
0,07 \\
14,59 \\
0,18 \\
9,37 \\
12,26 \\
0,02 \\
0,01 \\
1,50 \\
1,13 \\
1,94 \\
--08 \\
0,08 \\
98,91 \\
-0,04 \\
0,00\end{array}$ & $\begin{array}{r}39,10 \\
1,80 \\
11,23 \\
0,02 \\
26,43 \\
0,16 \\
2,80 \\
11,13 \\
0,03 \\
0,13 \\
1,60 \\
1,79 \\
1,74 \\
0,09 \\
0,18 \\
98,23 \\
-0,07 \\
-0,02\end{array}$ & $\begin{array}{r}37,69 \\
1,15 \\
13,92 \\
0,05 \\
25,87 \\
0,10 \\
2,57 \\
11,32 \\
0,05 \\
0,07 \\
1,52 \\
1,94 \\
1,70 \\
0,13 \\
0,24 \\
98,32 \\
-0,10 \\
-0,03\end{array}$ & $\begin{array}{r}43,06 \\
1,95 \\
12,70 \\
0,10 \\
12,90 \\
0,10 \\
11,18 \\
12,12 \\
0,04 \\
0,02 \\
1,69 \\
0,86 \\
1,97 \\
0,04 \\
0,06 \\
98,79 \\
-0,02 \\
-0,01\end{array}$ & $\begin{array}{r}39,21 \\
1,92 \\
11,26 \\
0,03 \\
26,59 \\
0,08 \\
3,26 \\
10,95 \\
0,02 \\
0,13 \\
1,62 \\
1,68 \\
1,76 \\
0,13 \\
0,14 \\
98,78 \\
-0,06 \\
-0,03\end{array}$ & $\begin{array}{r}44,14 \\
0,25 \\
12,85 \\
0,13 \\
12,79 \\
0,22 \\
11,96 \\
12,40 \\
0,04 \\
0,02 \\
1,70 \\
0,34 \\
2,00 \\
0,01 \\
0,05 \\
98,90 \\
-0,02 \\
0,00\end{array}$ & $\begin{array}{r}44,19 \\
2,14 \\
11,95 \\
0,13 \\
9,64 \\
0,05 \\
14,14 \\
12,01 \\
0,06 \\
0,01 \\
1,86 \\
1,03 \\
1,93 \\
- \\
0,24 \\
99,38 \\
-0,01 \\
0,00\end{array}$ \\
\hline TOTAL & 99,04 & 98,87 & 98,14 & 98,19 & 98,76 & 98,69 & 98,88 & 99,37 \\
\hline $\begin{array}{l}\text { T Si } \\
\text { T Al } \\
\text { T Fe' } \\
\text { T Ti } \\
\text { SOMA T } \\
\text { C Al } \\
\text { C Cr } \\
\text { C Fe' } \\
\text { C Ti } \\
\text { C Mg } \\
\text { C Fe } \\
\text { C Mn } \\
\text { C Ca } \\
\text { SOMA C } \\
\text { B Mg } \\
\text { B Fe } \\
\text { B Mn } \\
\text { B Ca } \\
\text { B Na } \\
\text { SOMA B } \\
\text { A Ca } \\
\text { A Na } \\
\text { A K } \\
\text { SOMA A } \\
\text { C Cl } \\
\text { C F } \\
\text { TOTAL } \\
\text { SOMA O }\end{array}$ & $\begin{array}{c}6,32 \\
1,68 \\
- \\
- \\
8,00 \\
0,79 \\
0,01 \\
0,01 \\
0,14 \\
2,29 \\
1,73 \\
0,03 \\
- \\
5,00 \\
- \\
- \\
2,00 \\
- \\
2,00 \\
- \\
0,42 \\
0,20 \\
0,62 \\
- \\
0,04 \\
15,62 \\
23,00\end{array}$ & $\begin{array}{c}6,14 \\
1,86 \\
: \\
- \\
8,00 \\
0,97 \\
0,01 \\
0,06 \\
0,10 \\
2,10 \\
1,75 \\
0,01 \\
5,00 \\
-01 \\
0,01 \\
0,01 \\
1,97 \\
0,01 \\
2,00 \\
- \\
0,42 \\
0,21 \\
0,63 \\
- \\
0,05 \\
15,63 \\
23,00\end{array}$ & $\begin{array}{c}6,36 \\
1,64 \\
\vdots \\
8,00 \\
0,52 \\
- \\
0,01 \\
0,22 \\
0,62 \\
3,57 \\
0,01 \\
5,00 \\
5,0 \\
0,02 \\
0,01 \\
1,94 \\
0,03 \\
2,00 \\
- \\
0,48 \\
0,38 \\
0,86 \\
0,02 \\
0,09 \\
15,86 \\
23,00\end{array}$ & $\begin{array}{c}6,09 \\
1,91 \\
- \\
- \\
8,00 \\
0,74 \\
- \\
0,12 \\
0,14 \\
0,62 \\
3,37 \\
0,01 \\
- \\
5,00 \\
0,02 \\
0,02 \\
0,01 \\
1,95 \\
0,02 \\
2,00 \\
- \\
0,44 \\
0,40 \\
0,84 \\
0,03 \\
0,11 \\
15,84 \\
23,00\end{array}$ & $\begin{array}{c}6,44 \\
1,56 \\
- \\
- \\
8,00 \\
0,68 \\
0,01 \\
- \\
0,22 \\
2,49 \\
1,59 \\
0,01 \\
-.00 \\
5,00 \\
- \\
0,02 \\
0,01 \\
1,94 \\
0,03 \\
2,00 \\
- \\
0,46 \\
0,16 \\
0,62 \\
0,01 \\
0,03 \\
15,62 \\
23,00\end{array}$ & $\begin{array}{c}6,31 \\
1,69 \\
- \\
- \\
8,00 \\
0,45 \\
- \\
0,12 \\
0,23 \\
0,78 \\
3,41 \\
0,01 \\
-.00 \\
5,00 \\
0,04 \\
0,01 \\
1,89 \\
0,06 \\
2,00 \\
- \\
0,45 \\
0,35 \\
0,80 \\
0,03 \\
0,07 \\
15,80 \\
23,00\end{array}$ & $\begin{array}{c}6,50 \\
1,50 \\
- \\
- \\
8,00 \\
0,75 \\
0,02 \\
0,17 \\
0,02 \\
2,62 \\
1,40 \\
0,02 \\
-. \\
5,00 \\
-, 01 \\
0,01 \\
0,01 \\
1,96 \\
0,02 \\
2,00 \\
5, \\
0,47 \\
0,06 \\
0,53 \\
-5 \\
0,02 \\
15,53 \\
23,00\end{array}$ & $\begin{array}{c}6,47 \\
1,53 \\
- \\
- \\
8,00 \\
0,54 \\
0,02 \\
0,04 \\
0,23 \\
3,08 \\
1,09 \\
- \\
- \\
5,00 \\
- \\
0,05 \\
- \\
1,89 \\
0,06 \\
2,00 \\
- \\
0,47 \\
0,22 \\
0,69 \\
- \\
0,09 \\
15,69 \\
23,00\end{array}$ \\
\hline
\end{tabular}

+ cianita + quartzo (Bohlen et al. 1983), que pode ocorrer no intervalo 9,5-14,5 kbar, e é observada nas rochas metassedimentares que envolvem a litologia amostrada.

A geotermobarometria indicou dois intervalos de condições metamórficas a região estudada: $830-900^{\circ} \mathrm{C}$ a $12,5-15,0 \mathrm{kbar}$, e $700-750^{\circ} \mathrm{C}$ a $10,5-13,0$ kbar. As temperaturas obtidas, plotadas no gráfico da reação de Bohlen et al. (1983), indicam pressões em torno de 12 kbar.

Ainda não existem dados termobarométricos suficientes para delimitar domínios metamórficos distintos para o Complexo Campos Gerais. Os dados petrográficos indicam, no entanto, diminuição do metamorfismo a partir da Zona de Cisalhamento Varginha em direção ao norte (Fig. 1), separando porções com características metamórficas próprias, as quais estão limitadas por zonas de cisalhamento (Zanardo 1992).

Nestas pesquisas, realizadas nas regiões de São Pedro da União e Nova Resende, ficou evidente que o pico metamórfíco é observado logo a norte da Zona de Cisalhamento Varginha e a sul de São Pedro da União. Verificou-se, também, que em virtude da diminuição das condições metamórficas, ocorreu a reação granada + clinopiroxênio $=$ anfibólio + plagioclásio, observada petrograficamente, que foi balizada em $670^{\circ} \mathrm{C}$ e 8,5 kbar por meio da composição química desses minerais, presentes em granada anfibolitos, utilizando os geotermômetros cpx-grt, grt-hbl e hbl-pl. As 
Tabela 5 - Análise de piroxênios por microssonda eletrônica

Table 5 - Electron microprobe analysis of pyroxene

\begin{tabular}{|c|c|c|c|c|}
\hline $\mathbf{P X}$ & 1 & 3 & 5 & 6 \\
\hline $\mathrm{SiO}_{2}$ & 51,47 & 52,09 & 50,39 & 51,60 \\
\hline $\mathrm{TiO}_{2}^{+}$ & 0,28 & 0,30 & 0,52 & 0,46 \\
\hline $\mathrm{Al}_{2} \overline{\mathrm{O}}_{3}$ & 3,21 & 2,84 & 7,78 & 4,35 \\
\hline $\mathrm{Cr}_{2} \mathrm{O}_{3}$ & 0,05 & 0,08 & 0,13 & 0,09 \\
\hline $\mathrm{Fe}_{2} \mathrm{O}_{3}$ & 1,42 & 0,79 & 1,33 & 1,95 \\
\hline $\mathrm{FeO}$ & 6,36 & 6,67 & 4,92 & 5,66 \\
\hline $\mathrm{MnO}$ & 0,19 & 0,13 & 0,06 & 0,06 \\
\hline $\mathrm{NiO}$ & - & 0,03 & 0,05 & 0,03 \\
\hline $\mathrm{MgO}$ & 12,38 & 13,04 & 11,67 & 13,16 \\
\hline $\mathrm{CaO}$ & 23,63 & 23,18 & 21,42 & 21,46 \\
\hline $\mathrm{Na}_{2} \mathrm{O}$ & 0,62 & 0,60 & 1,61 & 1.17 \\
\hline TOTAL & 99,61 & 99,75 & 99,88 & 99,99 \\
\hline $\mathrm{Si}^{+4}$ & 1,92 & 1,95 & 1,86 & $1,9]$ \\
\hline$T^{+4}$ & 0,01 & 0,01 & 0,01 & 0,01 \\
\hline $\mathrm{Al}^{+3}$ & 0,14 & 0,12 & 0,34 & 0,19 \\
\hline $\mathrm{Cr}^{+3}$ & $=$ & - & - & - \\
\hline $\mathrm{Fe}^{+3}$ & 0,04 & 0,02 & 0,04 & 0,05 \\
\hline $\mathrm{Fe}^{+2}$ & 0,20 & 0,21 & 0,15 & 0,17 \\
\hline $\mathbf{M n}^{+2}$ & 0,01 & - & - & - \\
\hline $\mathrm{Ni}^{+2}$ & - & - & - & - \\
\hline $\mathrm{Mg}^{+3}$ & 0,69 & 0.72 & 0,64 & 0,73 \\
\hline $\mathrm{Ca}^{+2}$ & 0,95 & 0,93 & 0,84 & 0,86 \\
\hline $\mathrm{Na}^{+1}$ & 0,04 & 0.04 & 0,12 & 0,08 \\
\hline TOTAL & 4,00 & 4,00 & 4,00 & 4,00 \\
\hline $0^{2}$ & 6,00 & 6,00 & 6,00 & 6,00 \\
\hline wo & 51,5 & 49,5 & 51,5 & 48,4 \\
\hline EN & 37,0 & 38,8 & 38,7 & 41,3 \\
\hline FS & 11,0 & 11,3 & 9,2 & 11,1 \\
\hline
\end{tabular}

condições retrometamórficas foram estimadas em $550^{\circ} \mathrm{C}$ e 6,5 kbar, mas devem ser inferiores, como apontam as paragêneses de gnaisses e rochas metabásicas, onde a presença de albita, a deformação do quartzo, a formação de clorita em rochas ácidas e stilpnomelano em fraturas, indicam, em certos locais, reajuste metamórfico em torno de $300-400^{\circ} \mathrm{C}$ (Zanardo 1992).

O presente estudo mostra uma boa concordância entre os valores encontrados com os termômetros cpx-grt e grt-hbl (Powell 1985), e do termômetro hbl-pl (Blundy \& Holland 1990), como mostrado na Tabela 6.
DISCUSSÃO As paragêneses observadas nas diversas rochas estudadas indicam que o metamorfismo ocorreu no limite superior da fácies anfibolito de alta pressão, e as de retrometamorfismo em fácies anfibolito-xisto verde, regredindo até a fácies xisto verde médio, quando submetidas à milonitização dúctil/rúptil a rüptil.

As paragêneses minerais e os dados termobarométricos da porção meridional do Complexo Campos Gerais indicam que o auge metamórfico ocorreu a temperaturas de $830-900^{\circ} \mathrm{C}$ e pressões de $12,5-15 \mathrm{kbar}$, como observado na amostra 5 (Tab. 6). Este intervalo indica ambiente de transição da fácies eclogito para granulito. Esses dados são obtidos pontualmente em rochas menos afetadas pelo retrometamorfismo.

Essas condições foram estimadas em granada anfibolitos situados a norte da Zona de Cisalhamento Varginha e a sul de São Pedro da União, os quais contêm a paragênese grt-cpx-qtz, podendo ser classificados como granulitos de alta pressão, segundo a classificação de Green \& Ringwood (1967).

Os dados termobarométricos indicam um patamar freqüente de temperaturas de $700-750^{\circ} \mathrm{C}$ e pressões de 10,5-13 kb, tanto para granada anfibolitos, quanto para gnaisses com anfibólio e granada.

Esses intervalos sugerem que as rochas estudadas podem ser parte de núcleos de rochas mais profundas preservadas dentro de uma região de complexa movimentação tectônica e trazidas para a superfície por cavalgamento.

As estimativas termobarométricas de $700-750^{\circ} \mathrm{C}$ e $10,5-$ 13 kbar são coerentes com os dados de Zanardo (1992), que apontaram, para a porção sul do Complexo Campos Gerais, temperaturas aproximadas de $740^{\circ} \mathrm{C}$ ou maiores, e pressões mínimas de 8,7 kbar, apresentando trajetórias no sentido horário, compatíveis com zonas de colisões continentais (Zanardo 1992, Del Lama et al. 1992).

Por outro lado, as temperaturas e pressões estimadas permitem inferir um grau geotérmico médio de $21^{\circ} \mathrm{C} / \mathrm{Km}$, para as rochas da porção sul do Complexo Campos Gerais, e são correlacionáveis com as do Grupo Araxá-Canastra.

Assim, as condições metamórficas estimadas para a faixa sul do Complexo Campos Gerais são compatíveis com regimes de pressão superior ao do tipo barrowiano, uma vez que, mesmo que a temperatura tenha ultrapassado $800^{\circ} \mathrm{C}$, não foi atingido o campo de estabilidade da sillimanita, comprovando os valores estimados para o grau geotérmico (Zanardo 1992).

Até o momento, os dados obtidos e os existentes na literatura, ainda não possibilitam a visualização da dinânica responsável pela atual configuração das diferentes unidades geológicas da região.

Agradecimentos Este trabalho teve o apoio financeiro da FAPESP (proc. $n^{9}$ 90/3984-8) e do convênio PADCT/ FINEP (n⿳⺈ 6.5.92.0040.00).

Tabela 6- Temperaturas e pressões estimadas para os pontos analisados $(\boldsymbol{P}=$ Powell 1985, $\boldsymbol{B} \boldsymbol{H}=$ Blundy \& Holland 1990, $\boldsymbol{H L}=$ Holdaway \& Lee 1977, $\boldsymbol{F S}=$ Ferry \& Spear 1978, NP= Newton \& Perkins 1982, KS = Kohn \& Spear 1990). Table 6 - Estimates of temperature and pressure for the studied rocks

\begin{tabular}{l|c|c|c|c|c|c|c|c|c}
\hline METODO & 1 & 2 & 3 & 4 & 5 & 6 & 7 & \multicolumn{2}{|c}{8} \\
\hline CPX-GRT (P) & 660 & 735 & 735 & 740 & 890 & 700 & - & - & ${ }^{\circ} \mathrm{C}$ \\
HBL-GRT (P) & 685 & 750 & 690 & 760 & 840 & 640 & - & - & ${ }^{\circ} \mathrm{C}$ \\
HBL-PL (BH) & 673 & 640 & 735 & 635 & 590 & 710 & 580 & 690 & ${ }^{\circ} \mathrm{C}$ \\
BT-GRT (HL/FS) & - & - & - & - & - & - & 580 & 690 & ${ }^{\circ} \mathrm{C}$ \\
GRT-CPX-PL-QTZ (NP) & 8,5 & - & 10,5 & - & 15,0 & 10,5 & - & - & $\mathrm{kb}$ \\
GRT-HBL-PL-QTZ (KS) & - & 12,8 & - & 13,0 & 11,0 & - & - & - & $\mathrm{kb}$ \\
\hline
\end{tabular}




\section{REFERÊNCIAS BIBLIOGRÁFICAS}

BLUNDY, J.D. \& HOLLAND, T.J.B. 1990. Calcic amphibole equilibria and a new amphibole-plagioclase geothermometer. Conlrib. Mineral Petrol, 104(2):208-224

BOHLEN, S.R; WALL, VJ \& BOETTCHER, A.L. 1983. Experimental investigations and geological applications of equilibria in the system FeO-TiO $-\mathrm{Al}_{2} \mathrm{O}_{3}-\mathrm{SiO}_{2}-\mathrm{H}_{2} \mathrm{O}$. Am. Mineral., 68:1049-1058.

CAVALCANTE, J.C.; CUNHA, H.C.da S.; CHIEREGATI, L.A.; KAEFER, L.Q.; ROCHA, J.M.da; DAITX, E.G.; COUTINHO, M.G.da N.; YAMAMOTO, K.; DRUMOND, J.B.V.; ROSA, D.B. \& RAMALHO, R. 1979. Projeto Sapucaí. Estados de São Paulo e Minas Gerais. DNPM/CPRM, Brasília, 299 p.

CRÓSTA, A.P; CHOUDHURI, A.; SZABÁ, G.A.J. \& SCHRANK, A. 1986. Relações entre Tipos Litológicos e suas Estruturas Regionais nos Terrenos Arqueanos e Proterozóicos do Sudoeste de Minas Gerais. In: CONGR. BRAS. GEOL., 34. Goiânia, 1986. Anais... Goiânia, SBG, v.2, p. 710-721.

DEER, W.A.; HOWIE, R.A. \& ZUSSMAN, J. 1966. Minerais constituintes das rochas - uma introdução. Lisboa: Fundação Calouste Gulbenkian, 558p.

DEL LAMA, E.A. 1993. Petrologia das rochas metamórficas de alto grau do Complexo Campos Gerais e correlação com as do Complexo Varginha-Cuaxupé - estudos termobarométricos. 132p. (Dissertação de Mestrado, IGCE-UNESP).

DEL LAMA, E.A.; ZANARDO, A.; MORALES, N. \& OLIVEIRA, M.A.F. de 1992. Metamorfísmo da porção sul do Complexo Campos Gerais. In: CONGR. BRÁS. GEOL., 37. São Paulo, 1992. Boletim... São Paulo, SBG. v. 1, p. 407-408

FERRY, J.M. \& SPEAR, F.S. 1978. Experimental calibration of the partitioning of the Fe and $\mathrm{Mg}$ between biotite and garnet. Contrib. Mineral. Petrol., 66:113-117.

GREEN, D.H. \& RING WOOD, A.E. 1967. An experimental investigation of the gabbro to eclogite transition and its petrological applications. Geochimica et Cosmochimica Acta, 31:767-833.

HEINRICH, E.Wm. 1965. Microscopic Identification of Minerals. McGraw-Hill Book Company. 414p.

HOLDAWAY, M.J. \& LEE, S.M. 1977. Fe-Mg cordierite stability in highgrade pelitic rocks based on experimental, theoretical, and natural observations. Contrib. Mineral. Petrol, 63:175-198.

HOPPE, A.; KLEIN, H.; CHOUDHRURI, A. \& SCHMIDT, W. 1985. Eclogitos pré-cambrianos no sudoeste de Minas Gerais. In: SIMP. GEOL. MINAS GERAIS, 3. Belo Horizonte, 1985. Anais... Belo Horizonte, SBG. p. 180-192.

KOHN, M.J. \& SPEAR, F.S. 1990. Two new geobarometers for garnet amphibolites, with applications to southeastern Vermont. Am. Mineral, 75(1/2):89-96.
LEAKE, B.E. 1978. Nomenclature of amphiboles. Am. Mineral, 63:1023-1052.

NEWTON, R.C. \& PERKINS III, D. 1982. Thermodynamic calibration of geobarometers based on the assemblages garnet - plagioclase - orthopyroxene (clinopyroxene) - quartz. Am. Mineral, 67:203-222.

POWELL, R. 1985. Regression diagnostics and robust regression in geothermometer/geobarometer calibration: the garnet clinopyroxene geothermometer revisited. /. Metamorphic Geol., 3:231 -243.

ROIG, H.L. \& SCHRANK, A. 1992. Caracterização da zona de sutura Jacuí-Conceição Aparecida - limite norte do Complexo de Nappes de Guaxupé - MG. In: CONGR. BRÁS. GEOL., 37. São Paulo, 1992. Boletim... São Paulo, SBG. v.1, p. 283-285.

SCHRANK, A.; ABREU, F.R.de; ROIG, H.L; CHOUDHURI, A.; SZABO, G.J.A. \& CARVALHO, E.D.R. 1990. Determinação dos Vetores de Transporte Tectônico na Borda Sudoeste do Cráton do São Francisco. In: CONGR. BRÁS. GEOL., 36. Natal, 1990. Anais... Natal, SBG. v. 5 , p. 2276-2283

SMULIKOWSKI, K. 1968. Differentiation of eclogites and its possible causes. Uthos, 1:89-101.

SOARES, P.C.; CARVALHO, S.G. de \&, FIORI, A.P. 1991. Evolução tectônica dos terrenos máficos e ultramáficos na margem sul do Cráton do São Francisco. In: Simp. Nac. Est. Tectônicos, 3. Rio Claro, 1991. Boletim... Rio Claro, SBG. p. 66-68.

SPEAR.F.S. 1981. Amphibole-plagioclase equilibria: an empirical model for the relation albite + tremolite $=$ edenite +4 quartz. Contrib. Mineral. Petrol., 77:355-364.

STOUT, J.H. 1972. Phase petrology and mineral chemistry of coexisting amphiboles fromTelemark, Norway. J. Petrology, 13(1):99-145.

TROUW. R.A.J.; RIBEIRO, A.; PACIULLO, F.V.P. \& HEILBRON, M.L. 1984. Os grupos São João Del Rei, Carrancas e Andrelândia, interpretados como a continuação dos grupos Araxá e Canastra. In: CONGR. BRAS. GEOL., 33. Rio de Janeiro, 1984. Anais... Rio de Janeiro, SBG. p. 3227-3240.

ZANARDO, A. 1992. Análise petrográfica, estratigráfica e microestrutural da região de Guaxupé-Passos-Delflnópolis $(M G) .288$ p. (Tese de Doutoramento, IGCE-UNESP).

MANUSCRITO A823

Recebido em 9 dezembro de 1994 Revisão do autor em 22 de setembro de 1995 Revisão aceita em 9 de fevereiro de 1996 